\title{
Infantile and adult heart rate patterns in cats during aversive conditioning
}

\author{
S. STEFAN SOLTYSIK, GEORGE WOLFE, JOSÉ GARCIA-SANCHEZ, \\ and THOMAS NICHOLAS \\ Mental Retardation Research Center, University of California, Los Angeles, California 90024
}

\begin{abstract}
Adult cats acquire complex heart rate response patterns to a CS paired with footshock US. The direction of the heart rate change in the last third of the CS-US interval is acceleratory when the subject performs a unilateral leg flexion, but a deceleration occurs when the motor response is a bilateral leg flexion (crouching) or immobility. In contrast, 4-week-old kittens show a uniform heart rate pattern that retains the same form whether the stimulus is novel, paired with the US, or unpaired. The amplitude of this infantile heart rate pattern undergoes habituation with unpaired presentations of the CS and US, but it is protected from habituation by the procedure of conditioning.
\end{abstract}

The deceleration of heart rate (HR) occurring as a "response" to a conditioned stimulus (CS) in cats conditioned with an aversive reinforcer (Bruner, 1969; Flynn, 1960; Giavelli, Astorga, \& Santibánez-H, 1977; Hein, 1969; Howard, Obrist, Gaebelein, \& Galosy, 1974; Jaworska, 1958; Santibánez-H, Saavedra, \& Middleton, 1963) is surprising if one considers that (1) animals display individual behaviors, even during the highly structured procedures of classical conditioning (cf. Gibson, 1952; Jaworska \& Soltysik, 1962), (2) HR is sensitive to a variety of organismic states and responses, including those obviously present in classical aversive conditioning (viz., orienting, startle, attention, active and passive defense, etc.), and (3) a classically conditioned response (CR) should, in principle, resemble the response elicited by the unconditioned stimulus (US), which in cats consists of HR acceleration. Thus one would expect HR in cats to accelerate and to be individually patterned in response to an aversive CS.

A reexamination of conditioned HR patterns in cats is warranted not only because previous studies on normal cats have yielded theoretically anomalous results, but also because the data from brain lesioned cats (Santibánez-H, Saavedra, \& Tisler, 1965), "transient" acceleratory responses noted in some normal cats (Bruner, 1969), and recent observations on kittens (Bloch \& Martinoya, 1981) have suggested the possibility of conditioned acceleratory HR responses in this species.

In this paper, an analysis is presented of HR data recorded during classical conditioning in cats and kittens. This study was different from most of the previous

This research was supported by HD 05958. The third author was Public Health Service International Research Fellow F05 TW 2478-02, and the fourth author was a postdoctoral trainee supported under HD 07032. Requests for reprints should be sent to Stefan Soltysik, MRRC, UCLA Los Angeles, California 90024. The authors are grateful to LeNae Boddie for her help in preparing this manuscript. reports on cats' HR conditioning in two important respects. First, the HR was not averaged over the CS-US interval, but, instead, it was sampled every $250 \mathrm{msec}$. Second, the subjects could walk or run on a treadmill during training. This freedom was allowed to minimize the tendency to freeze, which may be induced by excessive restriction of movements in an aversive situation (cf. Woodruff, 1977). Special attention was paid to discriminate a unilateral leg flexion $\mathrm{CR}$, which replicates the response to the US, from bilateral leg flexion, which in hammock-supported subjects corresponds to assuming a crouching posture.

\section{METHOD}

The subjects were 15 adult cats and 10 4-week-old kittens. Before the experiment, each subject was anesthetized with pentobarbital and surgically prepared with a cranial implant, which served as a means of firmly fixing the animal's head during training. An apparatus specially designed for the conditioning of cats and kittens allowed free movements of all limbs, walking, and running while restraining the subject. A description of the cranial implant and the apparatus is published elsewhere (Wolfe \& Soltysik, 1981). The CS was a tactile stimulus (airstream to the sacral region at 1-g force), and the US was a $4-\mathrm{mA} 60-\mathrm{Hz}$ shock of $300 \mathrm{msec}$ duration, delivered to the left hind leg (plantar surface) and the base of the tail. The CS duration was $5,200 \mathrm{msec}$. For each subject, the CS was presented five times alone to obtain the initial HR pattern elicited by this stimulus before training. Then, twice a day for 5 days, the CS and US were presented 10 times. In the conditioned subjects, the US was always presented $5,000 \mathrm{msec}$ after the CS onset. In the control subjects, the CS and US were presented on separate trials (i.e., unpaired). The intertrial interval varied from 2 to $4 \mathrm{~min}$. Leg flexion and EKG were collected by pen recording, and the HR was later entered into a computer through a digitizing tablet (Summagraphics, Inc.). Each subject's HR pattern was obtained by sampling the interbeat interval of EKG at 250-msec intervals and converting them into beat-per-minute scores. The HR scores from the last 20 trials (Sessions 9 and 10) were averaged into a single curve for each subject in order to define the individual HR pattern elicited by the CS (Figure 1); in Cat 7 only, the HR was rejected from 5 trials on which the animal ran (see below). 


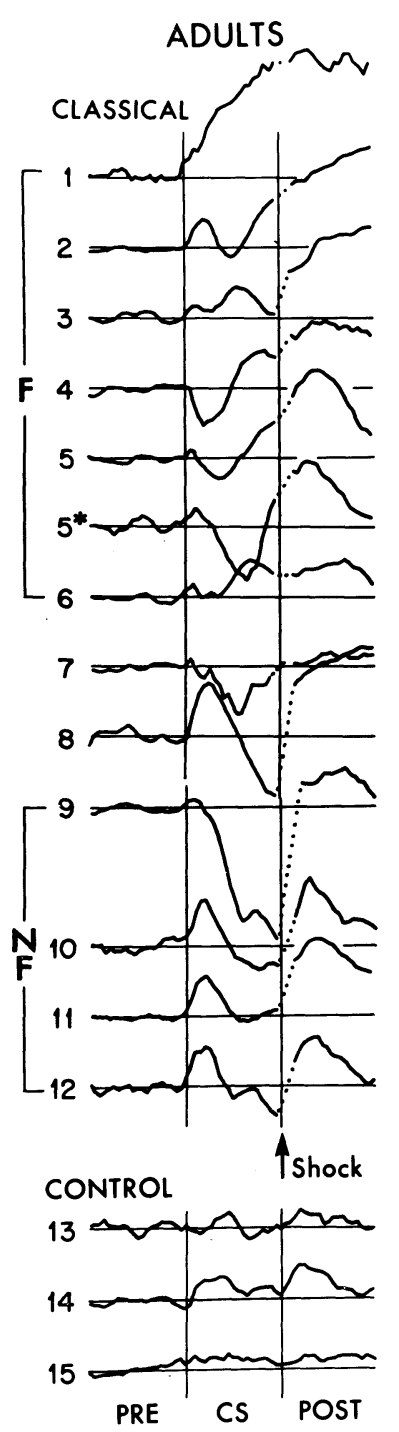

\section{KITTENS}

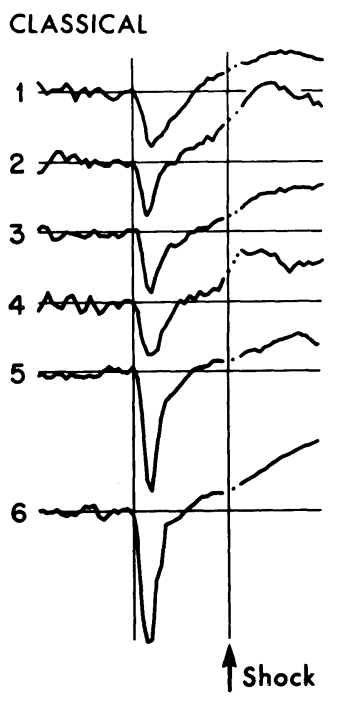

40 beats per min

$5 \mathrm{sec}$

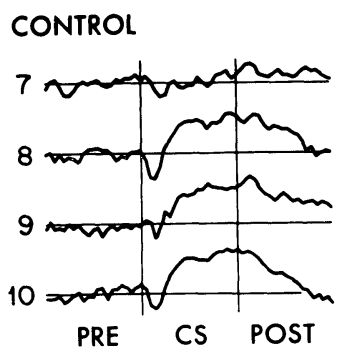

Figure 1. HR patterns in classically conditioned and control subjects. In each curve, the average HR during the last 20 acquisition trials is presented, starting $5 \mathrm{sec}$ before the CS onset (marked by the first vertical line) and ending $5 \mathrm{sec}$ after the CS termination (2nd vertical line). The discontinuities in the curves (dotted lines) are due to loss of the EKG during the shock US. The curve from Cat 5 is shown twice: from this study (Curve 5) and several months later (Curve $5^{*}$ ). Horizontal lines are preCS averaged HR baselines.

\section{RESULTS AND DISCUSSION}

All subjects flexed their hind leg in response to the shock. However, none of the kittens and only half of the cats acquired a unilateral leg flexion response to the CS. Cats that did not learn this response either remained motionless or flexed both hind legs, as if attempting to crouch. Of 12 adult cats, 6 consistently flexed their shocked hind leg during the CS (Bracket F in Figure 1), 4 were motionless (Bracket NF), 1 consistently performed a bilateral leg flexion (Cat 8), and the last

(Cat 7) flexed both hind legs on $75 \%$ of trials but ran on the remaining ones.

After training, the conditioned kittens showed virtually identical patterns of HR changes; however, the same pattern is recognizable in the control kittens (Figure 1), in spite of the apparent difference in mean HR deceleration (Figure 2). An inspection of the HR patterns shown in Figure 3 clearly indicates that the patterns are the same before and after conditioning and before and after unpaired presentation of the CS and US. A twotailed test for correlated groups suggests that the amplitude of the deceleration did not change in the conditioned group $[t(5)=.38, p>.7]$; however, it decreased significantly in the unpaired group $[\mathrm{t}(3)=3.38, \mathrm{p}<.05]$. A between-groups test showed that there was no difference in the mean HR deceleration before training $[t(8)=1.45, p>.1]$, but the two groups of kittens differed significantly after training $[\mathrm{t}(8)=3.60, \mathrm{p}<.01]$. The reduction in baseline HR that occurred between the first "habituation" trials and the 9th and 10th sessions (see Columns $\mathrm{H}$ and $9+10$ in the insert on Figure 3) were very similar in both groups of kittens and could not differentially affect the amplitude of the deceleratory response. This finding suggests that conditioning protected the preexisting response from habituation and that habituation of this response occurred in the control kittens.

The HR patterns in the 12 adult cats showed considerable variation, particularly in the first half of the CS-US interval. They ranged (Figure 1) from pure acceleration (Cat 1), through acceleration and deceleration (Cats 8, 10, and 12) or deceleration and acceleration (Cats 2, 4, 5, and 6), to almost monotonic decelera-

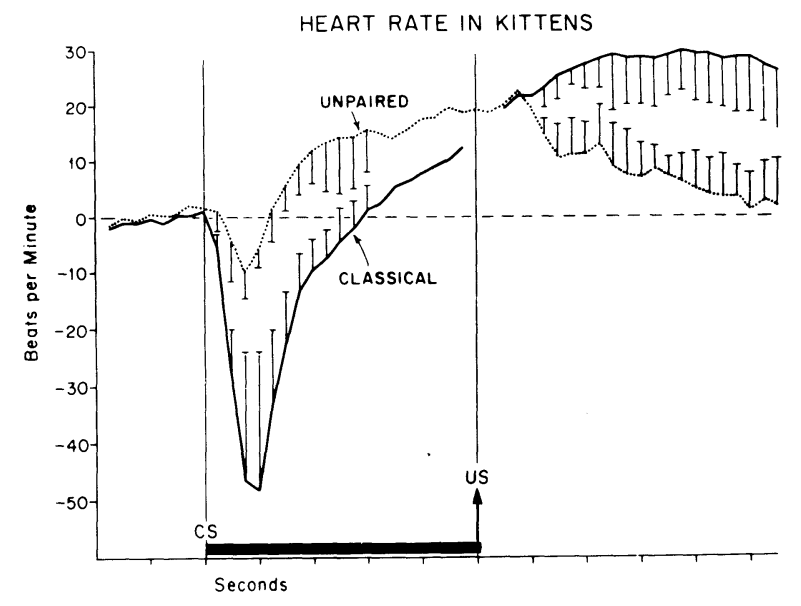

Figure 2. HR patterns in two groups of 4-week-old kittens. The solid line is an average HR pattern from subjects classically conditioned with a 5-sec CS-US interval; the dotted line is a HR pattern from control kittens. Vertical bars, which represent standard deviations, are shown for the points in these two curves, which differ significantly $(p<.05)$ by a two-tailed MannWhitney $U$ test (Siegel, 1956). The horizontal bar marks onset and termination of the CS. 


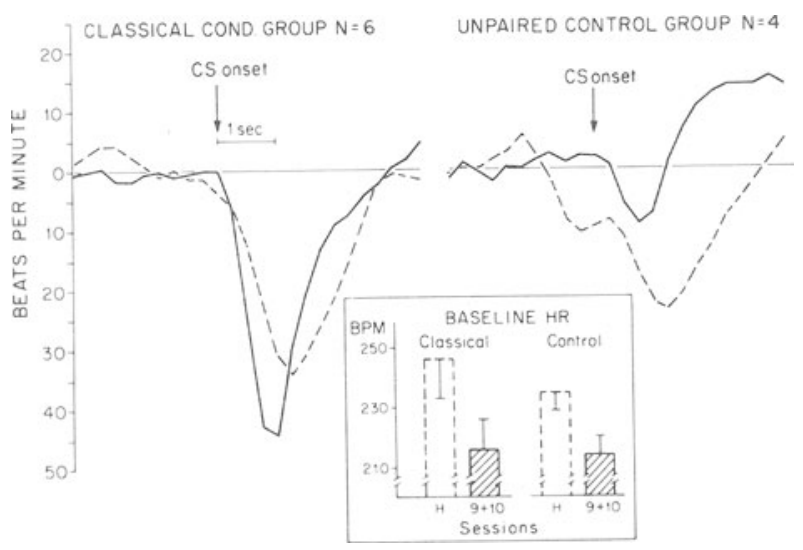

Figure 3. Comparison of the HR patterns to a CS before and after training in two groups of kittens. The left pair of curves represents averaged $H R$ responses in the conditioned kittens. The thin broken line is an HR response to a CS prior to conditioning, and the solid line is the HR response after conditioning. The right pair of curves represents the HR patterns to the same stimulus in the control kittens, before (broken line) and after (solid line) training. The baseline HR is subtracted so that the curves could be superimposed and compared. Columns in the insert compare the mean baseline HRs obtained from the 10-sec period prior to CS onset in the five initial (habituation) trials (Column $\mathrm{H}$ ) and in the last (9th and 10th) conditioning sessions.

Table 1

Acceleratory and Deceleratory. Heart Rate Changes in Three Consecutive 1.5-Sec Periods of the CS-US Interval Estimated by a Time-Series Analysis (Jones et al., 1969)

\begin{tabular}{|c|c|c|c|c|c|c|c|}
\hline \multirow{3}{*}{$\begin{array}{l}\text { Cate- } \\
\text { gory }\end{array}$} & \multicolumn{6}{|c|}{ Heart Rate Deviations From Baseline During: } & \multirow{3}{*}{$\begin{array}{l}\text { Overall } \\
\text { Pattern }\end{array}$} \\
\hline & \multicolumn{2}{|c|}{ First $1.5 \mathrm{Sec}$} & \multicolumn{2}{|c|}{ Second $1.5 \mathrm{Sec}$} & \multicolumn{2}{|c|}{ Third $1.5 \mathrm{Sec}$} & \\
\hline & $\mathrm{t}$ & $\mathrm{p}$ & $\mathrm{t}$ & $\mathrm{p}$ & $\mathrm{t}$ & $\mathrm{p}$ & \\
\hline 1 & 9.50 & .001 & 15.39 & .001 & 21.61 & .001 & AAA \\
\hline 2 & 7.75 & .001 & -5.12 & .001 & 7.89 & .001 & $\mathrm{ADA}$ \\
\hline 3 & 1.37 & $.1 *$ & 2.88 & .01 & 1.22 & $.2^{*}$ & $\mathrm{aAa}$ \\
\hline 4 & -14.51 & .001 & 7.04 & .001 & 7.30 & .001 & DAA \\
\hline 5 & -4.42 & .001 & 3.05 & .01 & 4.45 & .001 & DAA \\
\hline 6 & 2.53 & .02 & 4.93 & .001 & 6.55 & .001 & AAA \\
\hline 7 & 1.19 & $.2 *$ & -2.54 & .02 & -1.79 & $.05^{*}$ & $\mathrm{aDd}$ \\
\hline 8 & 5.50 & .001 & -1.17 & $.2 *$ & -3.39 & .01 & AdD \\
\hline 9 & 1.58 & $.1^{*}$ & -14.31 & .001 & -15.47 & .001 & $\mathrm{aDD}$ \\
\hline 10 & 8.29 & .001 & -2.10 & .05 & -4.73 & .001 & ADD \\
\hline 11 & 12.00 & .001 & 8.10 & .001 & -1.64 & $.1 *$ & AAd \\
\hline 12 & 7.70 & .001 & -3.34 & .01 & -5.26 & .001 & ADD \\
\hline
\end{tabular}

Note-In the last column, $A$ and $D$ are significant acceleratory and deceleratory changes and $a$ and $d$ denote nonsignificant acceleratory and deceleratory changes. $p<$ value given unless otherwise indicated. $\quad{ }^{*} p>$ value given.

tion (Cat 9). Table 1 presents the distribution of the acceleratory and deceleratory changes in the CS-US interval; their significance was assessed by a time-series analysis technique, which fits a first-order autoregressive model to the pre-CS baseline HR and then examines the deviations of observed from predicted values during the CS-US interval (Jones, Crowell, \& Kapuniai, 1969). The six cats (Cats 1-6) that responded consistently with a unilateral leg flexion showed HR acceleration in the last third of the CS-US interval, but a deceleration occurred in the first (Cats 4 and 5) and in the middle third (Cat 2). The cats that were motionless (Cats 9-12) or crouched (Cats 7 and 8) showed HR deceleration in the last third of the CS-US interval but tended to accelerate HR in the initial part of the CS. We conclude that the direction of the HR change occurring in anticipation of the shock US may be determined by the overall character of the behavior (active defensive, which allowed for the flexion response, or passive defensive, which seemed inhibitory and prevented the flexion) and not the presence or absence of the actual movement performed. These data also indicate that it is mandatory to observe the movements of both hind legs, lest the crouching response be mistakenly identified as flexion $\mathrm{CR}$.

No long-term study was undertaken to assess the stability of the individual patterns. Only in Cat 5 was there opportunity to observe the HR pattern after several months of training, and it remained essentially the same (Curves 5 and $5 *$ in Figure 1).

These data, in conjunction with previous studies, may indicate that the freedom to walk and a fine-grain analysis of HR patterns is necessary to reveal individually shaped conditioned behavior in the composition of the HR response patterns of adult cats. The concept of "compensatory response" (Bruner, 1969; Schneiderman, VanDercar, Yehle, Manning, Golden, \& Schneiderman, 1969; Yehle, Dauth, \& Schneiderman, 1967) invoked to explain the opposite directions of the CRs and unconditioned responses, is not supported by these findings. The HR responses to a signal of a painful US are acceleratory when the active and specific motor response is acquired. The deceleratory responses seem to be coupled with passive defensive behavior, an alternative mode of coping typically occurring in a stressful or "danger" situation (Archer, 1976; Engel \& Romano, 1947).

\section{REFERENCES}

Archer, J. The organization of aggression and fear in vertebrates. In P. P. G. Bateson \& P. Klopfer (Eds.), Perspectives in ethology (Vol. 2). New York: Plenum, 1976.

Bloch, S. A., \& Martinoya, C. Reactivity to light and development of classical cardiac conditioning in the kitten. Developmental Psychobiology, 1981, 14, 83-92.

BrUne R, A. Reinforcement strength in classical conditioning of leg flexion, freezing, and heart rate in cats. Conditional Reflex, 1969, 4, 24-31.

Engel, G. L., \& Romano, J. Studies of syncope: IV. Biologic interpretation of vasodepressor syncope. Psychosomatic Medicine, 1947, 9, 288-294.

FlynN, J. P. Discussion on papers by Reese and Gantt. Proceedings of a symposium on CNS control of circulation. Physiological Review, 1960, 40, 292-293.

Giavelli, A., Astorga, L., \& Santibanez-H., G. Effects of cardiac vagotomy on heart rate conditioned responses. Acta Neurobiologiae Experimentalis, 1977, 37, 179-190.

Gibson, E. J. The role of shock in reinforcement. Journal of Comparative and Physiological Psychology, 1952, 45, 18-30. 
Hein, P. L. Heart rate conditioning in the cat and its relationship to other physiological responses. Psychophysiology, 1969, 5, 455-464.

Howard, J. L., Obrist, P. A., Gaebelein, C. J., \& Galosy, R. A. Multiple somatic measures and heart rate during classical aversive conditioning in the cat. Journal of Comparative and Physiological Psychology, 1974, 87, 228-236.

JAworska, K. Conditional reflexes in cats after the removal of cerebellum. In The problems of comparative physiology of the nervous system. Leningrad: I.E.M. AMN USSR, 1958.

Jaworska, K., \& Soltysik, S. Studies on the aversive classical conditioning. 3. Cardiac responses to conditioned and unconditioned defensive (aversive) stimuli. Acta Biologiae Experimentalis, 1962, 22, 193-214.

Jones, R. H., Crowell, D. H., \& Kapuniai, L. E. Change detection model for serial correlated data. Psychological Bulletin, 1969, 71, 352-358.

Santibanez-H., G., SaAvedra, M. A., \& Middleton, S. Cardiac and respiratory concomitants in classical defensive conditioning in cats. Acta Biologiae Experimentalis, 1963, 23, 165-170.

Santibanez-H., G., SaAvedra, M. A., \& Tisler, S. Further studies on conditioned bradycardia in cats. Acta Biologiae Experimentalis, 1965, 25, 363-372.

Schneiderman, N., VanDercar, D. H., Yehle, A. L., Manning, A. A., Golden, T., \& Schneiderman, E. Vagal compensatory adjustment: Relationship to heart rate classical conditioning in rabbits. Journal of Comparative and Physiological Psychology, 1969, 68, 175-183.

Seigel, S. Nonparametric statistics. New York: McGraw-Hill, 1956.

Wolfe, G. E., \& Soltysik, S. S. An apparatus for behavioral and physiological study of aversive conditioning in cats and kittens. Behavior Research Methods \& Instrumentation, 1981, 13, 637-642.

WoodrufF, M. L. Limbic modulation of contact defensive immobility ("animal hypnosis"). Psychological Record, 1977, 29, 161-175.

Yehle, A., Dauth, G., \& Schneiderman, N. Correlates of heart-rate classical conditioning in curarized rabbits. Journal of Comparative and Physiological Psychology, 1967, 64, 98-104.

(Received for publication October 6, 1981.) 